\title{
Growth faltering and recovery in children aged $1-8$ years in four low- and middle-income countries: Young Lives
}

\author{
Elizabeth A Lundeen ${ }^{1}$, Jere R Behrman ${ }^{2}$, Benjamin T Crookston ${ }^{3}$, Kirk A Dearden ${ }^{4,5}$,

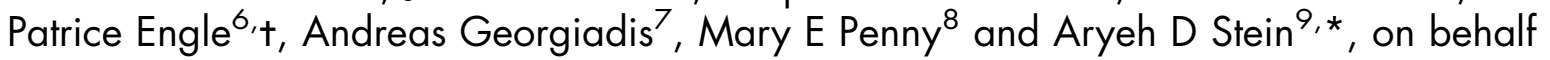 \\ of the Young Lives Determinants and Consequences of Child Growth Project Team: \\ 'Nutrition and Health Sciences, Graduate Division of Biological and Biomedical Sciences, Emory University, \\ Atlanta, GA, USA: ${ }^{2}$ Economics, Sociology and Population Studies Center, University of Pennsylvania, \\ Philadelphia, PA, USA: ${ }^{3}$ Department of Health Science, Brigham Young University, Provo, UT, USA: ${ }^{4}$ Department \\ of International Health and Center for Global Health and Development, Boston University, Boston, MA, USA: \\ ${ }^{5}$ Helen Keller International, Katmandu, Nepal: ${ }^{6}$ Department of Psychology and Child Development, Cal Poly \\ State University, San Luis Obispo, CA, USA: ${ }^{7}$ Young Lives Study, Department of International Development, \\ University of Oxford, Oxford, UK: ${ }^{8}$ Instituto de Investigación Nutricional, Lima, Peru and Massachusetts General \\ Hospital for Children, Harvard Medical School, Boston, MA, USA: ${ }^{9}$ Hubert Department of Global Health and \\ Department of Epidemiology, Rollins School of Public Health, Emory University, Mailstop 1518-002-7BB, Atlanta, \\ GA 30322, USA
}

Submitted 25 March 2013: Final revision received 26 August 2013: Accepted 23 September 2013: First published online 15 November 2013

\begin{abstract}
Objective: We characterized post-infancy child growth patterns and determined the incidence of becoming stunted and of recovery from stunting. Design: Data came from Young Lives, a longitudinal study of childhood poverty in four low- and middle-income countries.

Setting: We analysed length/height measurements for children at ages 1, 5 and 8 years.

Subjects: Children ( $n$ 7171) in Ethiopia, India, Peru and Vietnam.

Results: Mean height-for-age $Z$-score (HAZ) at age 1 year ranged from -1.51 (Ethiopia) to $-1 \cdot 08$ (Vietnam). From age 1 to 5 years, mean HAZ increased by 0.27 in Ethiopia $(P<0 \cdot 001)$ and decreased among the other cohorts (range: $-0 \cdot 19$ (Peru) to $-0 \cdot 32$ (India); all $P<0 \cdot 001$ ). From 5 to 8 years, mean HAZ increased in all cohorts (range: 0.19 (India) to 0.38 (Peru); all $P<0 \cdot 001$ ). Prevalence of stunting $(\mathrm{HAZ}<-2 \cdot 0)$ at 1 year ranged from $21 \%$ (Vietnam) to $46 \%$ (Ethiopia). From age 1 to 5 years, stunting prevalence decreased by $15 \cdot 1$ percentage points in Ethiopia $(P<0 \cdot 001)$ and increased in the other cohorts (range: 3.0 percentage points (Vietnam) to 5.3 percentage points (India); all $P \leq 0 \cdot 001$ ). From 5 to 8 years, stunting prevalence decreased in all cohorts (range: $5 \cdot 0$ percentage points (Vietnam) to $12 \cdot 7$ percentage points (Peru); all $P<0 \cdot 001$ ). The incidence of becoming stunted between ages 1 to 5 years ranged from $11 \%$ (Vietnam) to $22 \%$ (India); between ages 5 to 8 years, it ranged from 3\% (Peru) to $6 \%$ (India and Ethiopia). The incidence of recovery from stunting between ages 1 and 5 years ranged from $27 \%$ (Vietnam) to $53 \%$ (Ethiopia); between ages 5 and 8 years, it ranged from $30 \%$ (India) to $47 \%$ (Ethiopia).

Conclusions: We found substantial recovery from early stunting among children in four low- and middle-income countries.
\end{abstract}

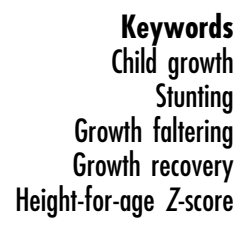

Characterizing child growth patterns, including the incidence of becoming stunted and of recovery from stunting,

\footnotetext{
$\dagger$ Deceased.

$\$$ The Young Lives Determinants and Consequences of Child Growth Project team includes, in addition to the co-authors of this paper: Santiago Cueto, Le Thuc Duc, Javier Escobal, Lia Fernald, Shaik Galab, Nafisa Halim, Priscila Hermida, Subha Mani, Tassew Woldehanna and Whitney Schott.
}

in low- and middle-income countries (LMIC) is important for understanding the determinants and consequences of childhood growth trajectories and for developing effective interventions and policies. Cross-sectional data from the Demographic and Health Surveys show that on average children in LMIC experience rapid growth faltering during the first two years of life, with height-for-age $Z$-score (HAZ), the preferred indicator of long-run nutritional status, 
declining dramatically over the first 24 months of life and increasing only slightly thereafter ${ }^{(1)}$. These and similar findings have been used to suggest that recovery after 2 years of age is unlikely and therefore the 'window of opportunity' for preventing undernutrition ends at age 2 years.

Nutritional interventions are increasingly targeted towards children under 2 years old as it has been suggested that, similar to linear growth retardation, the cognitive and developmental deficiencies resulting from poor growth may also be largely irreversible after about 2 years of age ${ }^{(2-8)}$. However, some evidence challenges these findings ${ }^{(9-17)}$ and suggests that there is significant opportunity for catch-up growth, as well as the associated cognitive and schooling improvements, following post-infancy growth stunting. Such evidence may support a complementary approach focused on identifying and targeting children post-infancy who are stunted or at risk for growth faltering, for further nutritional or health interventions. There are few published longitudinal studies of child growth and its consequences for health and development (that by Adair (1999) ${ }^{(18)}$ is an exception), limiting the conclusions that can be drawn about child growth trajectories in LMIC.

Our study addresses this gap in the literature by presenting longitudinal child growth data from populationbased cohorts in four LMIC. We analysed data on the growth patterns of children post-infancy ( $\geq 12$ months), in order to describe growth patterns and determine the incidence of becoming stunted and of recovery from stunting.

\section{Participants and methods}

\section{Young Lives study}

Young Lives is a longitudinal study of the causes and consequences of childhood poverty in Peru, Vietnam, India and Ethiopia ${ }^{(19)}$. Within each country, the study follows a cohort of $\sim 2000$ children (there is also an older cohort of about half this size). The Young Lives Project used a multistage sampling strategy, whereby the first stage consisted of the selection of twenty sentinel sites (clusters) per country using a sampling methodology referred to as the Sentinel Site Surveillance System. In each country, the sentinel sites were selected in a semi-purposive manner based on socio-economic, demographic, geographic and policy variables that were relevant to the project. In Peru, Vietnam and Ethiopia, a nationwide sampling frame was used, whereas in India the sentinel sites were selected within the state of Andhra Pradesh. The sampling frame allowed for oversampling of poor areas and a mixture of urban and rural areas. In the second stage, within each sentinel site, households with a child in the target age range were enumerated and approximately 100 index children were selected according to comparable, but country-specific, protocols that were analogous to statistical random sampling. Refusal rates among selected households were $<2 \%$ in all four countries and in the case of refusal, replacement sampling was used ${ }^{(19)}$. These sampling methods resulted in a sample for each country that reflected the ethnic, geographic and religious diversity of the population, but that was not chosen to be directly nationally representative. Further details on the sampling strategy used within each country can be found in the Preliminary National Reports (accessible at http:/ www.younglives.org.uk/). Data collection took place in 2002 (round 1, age 6 to 18 months), in 2006-2007 (round 2 , age 4.5 to 5 years) and in 2009-2010 (round 3, age 7 to 8 years). Supine length (round 1) and standing height (rounds 2 and 3) were measured with length/height boards using standardized WHO methodology ${ }^{(20)}$ and measurements precise to $1 \mathrm{~mm}$. The length and height measurements were converted to $Z$-scores (HAZ) using WHO standards ${ }^{(21-23)}$.

\section{Data cleaning and analysis}

Length measurements were available at recruitment for 1946 children in Ethiopia, 1992 children in India, 2040 children in Peru and 1990 children in Vietnam. Data were excluded from analysis if the child: was not in the target age range (6-17.9 months) at recruitment (zero children in Ethiopia, thirty-nine in India, twenty-seven in Peru and sixty-nine in Vietnam); was not measured at all three rounds (115 children in Ethiopia, eighty-seven in India, 146 in Peru and seventy-two in Vietnam); or had HAZ values that were implausible, defined as |HAZ | $>5$ at any one round or an absolute value of change in HAZ between rounds of $>4$ (121 children in Ethiopia, seventy in India, thirty-two in Peru and nineteen in Vietnam). After these exclusions, data were available for 7171 children (1710 in Ethiopia, 1796 in India, 1835 in Peru and 1830 in Vietnam), representing 90\% of the original sample.

Children who were younger at recruitment tended to have higher HAZ values and children who were older at recruitment tended to have lower HAZ values (Fig. 1). Failing to account for the variability in age at recruitment would distort an assessment of the incidence of becoming stunted and of recovery between rounds 1 and 2, because children who were older than 12 months at round 1 would be coded as having greater recovery than they otherwise would have had they been recruited at 12 months, while children who were younger than 12 months at round 1 would be coded as having greater incidence of stunting than they otherwise would have, assuming that over short periods of time children track along the growth trajectory that is typical of the community in which they live. Therefore, we adjusted round 1 HAZ by adding the difference between the child's observed HAZ and the sitespecific mean HAZ for all children within \pm 1 month of the child's age to the site-specific mean HAZ for children aged 11-13 months. Overall, there was little difference by month of age in mean HAZ in rounds 2 and 3, and 


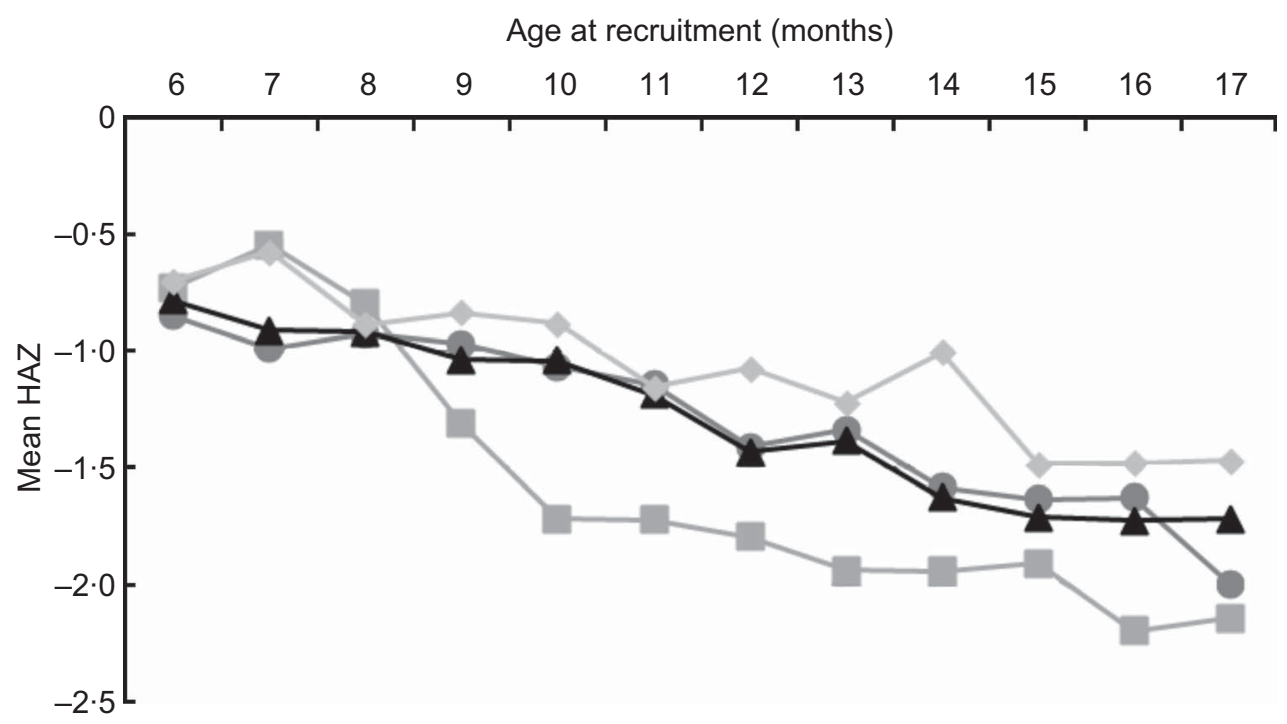

Fig. 1 Mean height-for-age $Z$-score (HAZ) at round 1 by age at recruitment in months among children ( $n 7171)$ in four low- and middle-income countries (-- Ethiopia; $-\leftarrow$, India; $\_-$, Peru; $\_$, Vietnam); the Young Lives study

therefore we did not conduct a similar adjustment for these rounds.

\section{Characterizing growth}

We compared the mean values for HAZ at each round and the mean within-child change in HAZ between rounds. We computed the prevalence of stunting (HAZ $<-2 \cdot 0)$ in each round as well as the incidence of becoming stunted (the proportion of children who were not stunted in an earlier round but were stunted at a later round) and of recovery (the proportion of children who were stunted in an earlier round but were not stunted at a later round). Tests of statistical significance were carried out using linear regression analyses that accounted for both the paired nature of the data as well as the clustering within the data due to sampling procedures; all $P$ values presented are two-sided. We also determined the extent to which HAZ measurements at earlier ages predict HAZ at later ages by performing the regression of HAZ at round 2 $v$. HAZ at round 1 , and the regression of HAZ at round 3 $v$. HAZ at rounds 1 and 2 . We used the Intercooled STATA $10 \cdot 0$ statistical software package for all data analyses.

\section{Results}

The average age at recruitment was $12 \cdot 2$ months, with some variation across cohorts (Table 1 ). At round 1 , the Ethiopian cohort had the lowest mean HAZ $(-1.51)$ and the Vietnamese cohort had the highest $(-1 \cdot 08$; Table 2$)$. From round 1 to round 2, mean HAZ increased among Ethiopian children $(0 \cdot 27 ; P<0 \cdot 001)$ and decreased among the other cohorts (range: $-0 \cdot 19$ to $-0 \cdot 32$; all $P<0 \cdot 001$ ). From round 2 to round 3 , mean HAZ increased in all four cohorts (range: $0 \cdot 19$ to $0 \cdot 38$; all $P<0 \cdot 001$ ). At round 1 , the Ethiopian cohort had the highest prevalence of stunting (46\%) and the Vietnamese cohort had the lowest (21\%). From round 1 to round 2, the Ethiopian cohort experienced a $15 \cdot 1$ percentage points (PP) reduction in the prevalence of stunting $(P<0 \cdot 001)$, while the stunting prevalence increased (range: $3 \cdot 0$ to $5 \cdot 3 \mathrm{PP}$; all $P \leq 0 \cdot 001$ ) in the other three cohorts. From round 2 to round 3 , the prevalence of stunting decreased (range: $5 \cdot 0$ to $12 \cdot 7 \mathrm{PP}$; all $P<0 \cdot 001$ ) in all four cohorts. Taking the whole study period, from round 1 to round 3 , there was a significant decrease in the stunting prevalence in Ethiopia (25.4 PP; $P<0.001)$, Peru (8.3 PP; $P<0 \cdot 001)$ and Vietnam (2.0 PP; $P=0 \cdot 04)$; however, the decrease of $0 \cdot 8 \mathrm{PP}$ in India was not significant $(P=0 \cdot 45)$.

From round 1 to round 2 , the majority of children had a change in $H A Z \geq 0 \cdot 50$ (Fig. 2), whereas from round 2 to round 3 , the majority of children experienced a change in $\mathrm{HAZ} \leq 0 \cdot 49$.

The incidence of becoming stunted from round 1 to round 2 ranged from $11 \%$ (Vietnam) to $22 \%$ (India; Table 3), and from round 2 to round 3 ranged from $3 \%$ (Peru) to $6 \%$ (India and Ethiopia). The incidence of recovery ranged from $27 \%$ (Vietnam) to $53 \%$ (Ethiopia) between rounds 1 and 2, and from 30\% (India) to $47 \%$ (Ethiopia) between rounds 2 and 3. From round 1 to round 3, the incidence of becoming stunted ranged from $8 \%$ (Peru) to $18 \%$ (India) and the incidence of recovery ranged from $45 \%$ (Vietnam) to $67 \%$ (Ethiopia).

In the regression of HAZ at round $2 v$. HAZ at round 1 , the $r^{2}$ was 0.26 in Ethiopia, 0.33 in India, 0.47 in Peru and 0.60 in Vietnam; therefore, between 26 and $60 \%$ of the variability in HAZ at round 2 was predicted by HAZ at round 1 . In the regression of HAZ at round $3 v$. HAZ at rounds 1 and 2, the $r^{2}$ was 0.53 in Ethiopia, 0.65 in India, 
0.71 in Peru and 0.73 in Vietnam; therefore, between 53 and $73 \%$ of the variability in HAZ at round 3 was predicted by HAZ at rounds 1 and 2 .

\section{Discussion}

We analysed child growth patterns using HAZ at ages 1, 5 and 8 years of 7171 children in four LMIC participating in

Table 1 Baseline characteristics of children in the Young Lives cohorts* $^{*}$

\begin{tabular}{lcrrr}
\hline Characteristic & Ethiopia & India & Peru & Vietnam \\
\hline Number of children & 1710 & 1796 & 1835 & 1830 \\
Age at recruitment (months) & & & & \\
Mean & $12 \cdot 2$ & $12 \cdot 2$ & $12 \cdot 0$ & $12 \cdot 3$ \\
SD & $3 \cdot 6$ & $3 \cdot 4$ & $3 \cdot 5$ & $3 \cdot 1$ \\
Male (\%) & $53 \cdot 2$ & $53 \cdot 4$ & $50 \cdot 1$ & $51 \cdot 2$ \\
\hline
\end{tabular}

*Based on children in the present analysis. the Young Lives study. Cross-sectional data from round 1 demonstrated decreasing mean HAZ between the ages 6 and 18 months. Three of the four countries continued to experience declining HAZ between ages 1 year and 5 years. Mean HAZ increased in all four countries between ages 5 years and 8 years. While stunting status at round 1 was predictive of stunting at rounds 2 and 3, there was substantial recovery from early stunting, with recovery rates ranging from $27 \%$ to $53 \%$ between rounds 1 and 2 , and from $30 \%$ to $47 \%$ between rounds 2 and 3. Intrachild height measurements over time are highly correlated, reflecting a combination of genetic predisposition and environmental influences that affect linear growth. However, a substantial proportion of the variability in HAZ at age 5 years (40-74\%) and in HAZ at age 8 years (27-47\%) was not predicted by HAZ measurements at earlier time points.

The data we used were collected through a large, multi-country longitudinal study, using standardized

Table 2 Height-for-age Z-score (HAZ) measures at ages 1 year, 5 years and 8 years, and changes in HAZ between these ages, by country, among children $(n$ 7171) in four low- and middle-income countries; the Young Lives study

\begin{tabular}{|c|c|c|c|c|c|c|c|c|c|c|c|c|}
\hline & \multicolumn{3}{|c|}{ Ethiopia ( $n$ 1710) } & \multicolumn{3}{|c|}{ India (n 1796) } & \multicolumn{3}{|c|}{ Peru (n 1835) } & \multicolumn{3}{|c|}{ Vietnam (n 1830) } \\
\hline & Mean & SD & Range & Mean & SD & Range & Mean & SD & Range & Mean & SD & Range \\
\hline $\begin{array}{l}\text { HAZ, round } 1 \text { (age } 1 \text { year) } \\
\text { HAZ, round } 2 \text { (age } 5 \text { years) } \\
\text { HAZ, round } 3 \text { (age } 8 \text { years) } \\
\text { HAZ change, rounds } 1 \text { to } 2 \\
\text { HAZ change, rounds } 2 \text { to } 3\end{array}$ & $\begin{array}{r}-1 \cdot 51 \\
-1 \cdot 46 \\
-1 \cdot 21 \\
0 \cdot 27 \\
0 \cdot 25\end{array}$ & $\begin{array}{l}1 \cdot 58 \\
1 \cdot 04 \\
1 \cdot 00 \\
1 \cdot 35 \\
0 \cdot 78\end{array}$ & $\begin{array}{l}-4 \cdot 98,4 \cdot 59 \\
-4 \cdot 84,2 \cdot 00 \\
-4 \cdot 87,3 \cdot 56 \\
-3 \cdot 84,3 \cdot 92 \\
-2 \cdot 56,3 \cdot 99\end{array}$ & $\begin{array}{r}-1 \cdot 30 \\
-1 \cdot 63 \\
-1 \cdot 43 \\
-0 \cdot 32 \\
0 \cdot 19\end{array}$ & $\begin{array}{l}1 \cdot 35 \\
0.95 \\
0.99 \\
1 \cdot 11 \\
0.62\end{array}$ & $\begin{array}{l}-4 \cdot 87,4 \cdot 61 \\
-4 \cdot 71,3 \cdot 13 \\
-4 \cdot 87,2 \cdot 21 \\
-3 \cdot 99,3 \cdot 89 \\
-3 \cdot 23,3 \cdot 93\end{array}$ & $\begin{array}{r}-1 \cdot 29 \\
-1 \cdot 51 \\
-1 \cdot 13 \\
-0 \cdot 19 \\
0 \cdot 38\end{array}$ & $\begin{array}{l}1 \cdot 22 \\
1 \cdot 08 \\
1 \cdot 02 \\
0 \cdot 90 \\
0 \cdot 62\end{array}$ & $\begin{array}{l}-4 \cdot 95,3 \cdot 23 \\
-4 \cdot 61,2 \cdot 05 \\
-4 \cdot 29,2 \cdot 17 \\
-3 \cdot 78,3 \cdot 51 \\
-2 \cdot 31,3 \cdot 62\end{array}$ & $\begin{array}{r}-1 \cdot 08 \\
-1 \cdot 33 \\
-1 \cdot 09 \\
-0.21 \\
0.24\end{array}$ & $\begin{array}{l}1 \cdot 15 \\
1 \cdot 01 \\
1 \cdot 03 \\
0 \cdot 72 \\
0 \cdot 55\end{array}$ & $\begin{array}{l}-4 \cdot 94,3 \cdot 81 \\
-4 \cdot 65,2 \cdot 87 \\
-4 \cdot 50,2 \cdot 88 \\
-3 \cdot 58,3 \cdot 52 \\
-3 \cdot 42,3 \cdot 40\end{array}$ \\
\hline & \multicolumn{3}{|c|}{$\%$} & \multicolumn{3}{|c|}{$\%$} & \multicolumn{3}{|c|}{$\%$} & \multicolumn{3}{|c|}{$\%$} \\
\hline \multicolumn{13}{|l|}{ Stunting $(\mathrm{HAZ}<-2 \cdot 0)$} \\
\hline $\begin{array}{l}\text { Round } 1 \text { (age } 1 \text { year) } \\
\text { Round } 2 \text { (age } 5 \text { years) } \\
\text { Round } 3 \text { (age } 8 \text { years) }\end{array}$ & & $\begin{array}{l}45 \cdot 5 \\
30 \cdot 4 \\
20 \cdot 1\end{array}$ & & & $\begin{array}{l}29 \cdot 3 \\
34 \cdot 6 \\
28 \cdot 5\end{array}$ & & & $\begin{array}{l}27 \cdot 9 \\
32 \cdot 3 \\
19 \cdot 6\end{array}$ & & & $\begin{array}{l}21 \cdot 2 \\
24 \cdot 2 \\
19 \cdot 2\end{array}$ & \\
\hline
\end{tabular}

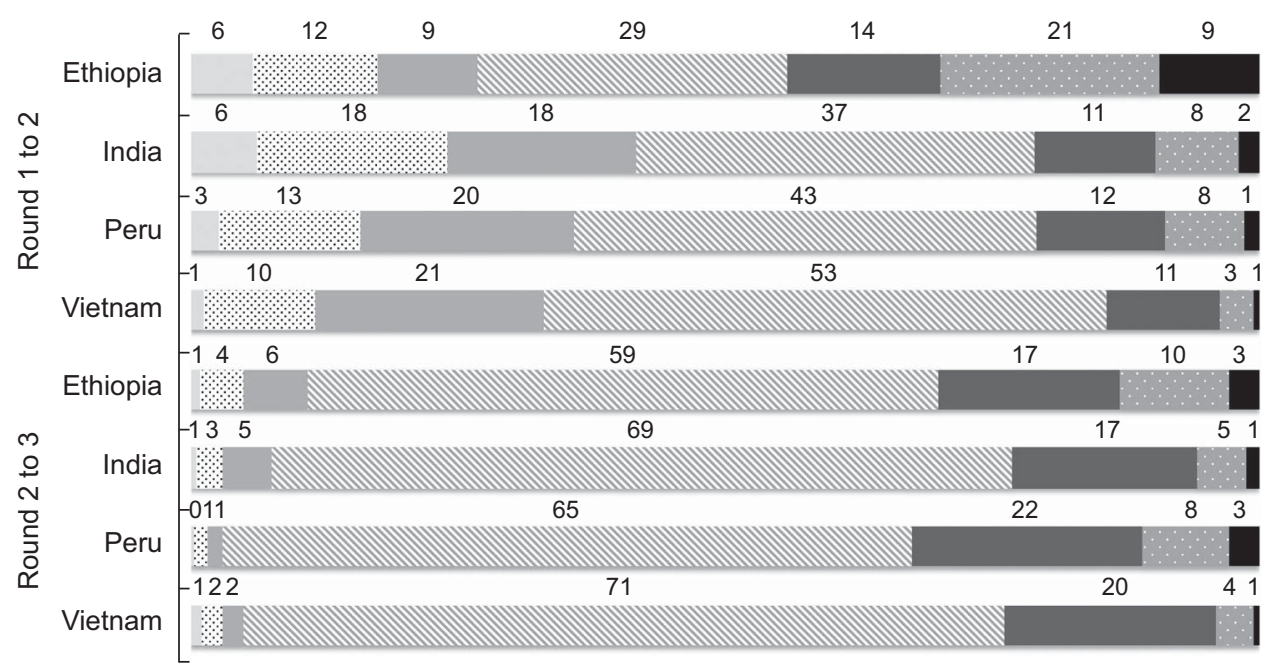

Fig 2 Categories of change in height-for-age Z-score (HAZ) between rounds ( , decrease in $\mathrm{HAZ}$ of $\geq 2 \cdot 00 ; \because$, decrease in $\mathrm{HAZ}$ of $1.00-1.99$; , decrease in HAZ of $0.50-0.99$;, change in HAZ within -0.49 to +0.49 ; , increase in $\mathrm{HAZ}$ of $0.50-0.99$; increase in HAZ of 1.00-1.99; $\mathbf{n}$, increase in HAZ of $\geq 2 \cdot 00$ ), by country, among children ( $n$ 7171) in four low- and middle-income countries; the Young Lives study. Bars represent the percentages of children in each category of HAZ change 
Table 3 Incidence of stunting ${ }^{\star}$ and of recoveryt from stunting, by country, among children $(n$ 7171) in four low- and middle-income countries; the Young Lives study

\begin{tabular}{|c|c|c|c|c|c|c|c|}
\hline \multirow[b]{2}{*}{ Country } & \multirow[b]{2}{*}{ Round } & \multirow[b]{2}{*}{ HAZ status } & \multirow[b]{2}{*}{ Status at round $1(\%)$} & \multicolumn{2}{|c|}{ Status at round $2(\%)$} & \multicolumn{2}{|c|}{ Status at round $3(\%)$} \\
\hline & & & & $\mathrm{HAZ}<-2 \cdot 0$ & $H A Z \geq-2 \cdot 0$ & $\mathrm{HAZ}<-2 \cdot 0$ & $\mathrm{HAZ} \geq-2 \cdot 0$ \\
\hline \multirow[t]{2}{*}{ Ethiopia ( $n$ 1710) } & 1 & $\mathrm{HAZ}<-2 \cdot 0$ & $45 \cdot 5$ & $47 \cdot 4$ & $52 \cdot 6$ & $32 \cdot 9$ & $67 \cdot 1$ \\
\hline & & $H A Z \geq-2 \cdot 0$ & $54 \cdot 5$ & $16 \cdot 1$ & $83 \cdot 9$ & $9 \cdot 3$ & $90 \cdot 7$ \\
\hline \multirow[t]{2}{*}{ India (n 1796) } & 1 & $\mathrm{HAZ}<-2 \cdot 0$ & $29 \cdot 3$ & $65 \cdot 3$ & $34 \cdot 7$ & $54 \cdot 3$ & $45 \cdot 7$ \\
\hline & & $H A Z \geq-2 \cdot 0$ & $70 \cdot 7$ & $21 \cdot 9$ & $78 \cdot 1$ & $17 \cdot 7$ & $82 \cdot 3$ \\
\hline \multirow[t]{2}{*}{ Peru (n 1835) } & 1 & $\mathrm{HAZ}<-2 \cdot 0$ & $27 \cdot 9$ & $69 \cdot 7$ & $30 \cdot 3$ & $49 \cdot 2$ & $50 \cdot 8$ \\
\hline & & $\mathrm{HAZ} \geq-2 \cdot 0$ & $72 \cdot 1$ & $17 \cdot 8$ & $82 \cdot 2$ & $8 \cdot 1$ & $91 \cdot 9$ \\
\hline \multirow[t]{3}{*}{ Vietnam (n 1830) } & 1 & $\mathrm{HAZ}<-2 \cdot 0$ & $21 \cdot 2$ & $72 \cdot 9$ & $27 \cdot 1$ & $54 \cdot 8$ & $45 \cdot 2$ \\
\hline & & $H A Z \geq-2 \cdot 0$ & $78 \cdot 8$ & $11 \cdot 2$ & $88 \cdot 8$ & $9 \cdot 6$ & $90 \cdot 4$ \\
\hline & & & Status at round $2(\%)$ & & & & \\
\hline \multirow[t]{2}{*}{ Ethiopia ( $n$ 1710) } & 2 & $\mathrm{HAZ}<-2 \cdot 0$ & $30 \cdot 4$ & & & $52 \cdot 6$ & $47 \cdot 4$ \\
\hline & & $H A Z \geq-2 \cdot 0$ & $69 \cdot 6$ & & & $5 \cdot 9$ & $94 \cdot 1$ \\
\hline \multirow[t]{2}{*}{ India (n 1796) } & 2 & $\mathrm{HAZ}<-2 \cdot 0$ & $34 \cdot 6$ & & & $70 \cdot 3$ & $29 \cdot 7$ \\
\hline & & $H A Z \geq-2 \cdot 0$ & $65 \cdot 4$ & & & $6 \cdot 3$ & $93 \cdot 7$ \\
\hline \multirow[t]{2}{*}{ Peru (n 1835) } & 2 & $\mathrm{HAZ}<-2 \cdot 0$ & $32 \cdot 3$ & & & $53 \cdot 9$ & $46 \cdot 1$ \\
\hline & & $H A Z \geq-2 \cdot 0$ & $67 \cdot 7$ & & & $3 \cdot 2$ & $96 \cdot 8$ \\
\hline \multirow[t]{2}{*}{ Vietnam ( $n$ 1830) } & 2 & $\mathrm{HAZ}<-2 \cdot 0$ & $24 \cdot 2$ & & & $65 \cdot 2$ & $34 \cdot 8$ \\
\hline & & $\mathrm{HAZ} \geq-2 \cdot 0$ & $75 \cdot 8$ & & & $4 \cdot 5$ & $95 \cdot 5$ \\
\hline
\end{tabular}

HAZ, height-for-age Z-score.

*Incidence of stunting is the proportion of children who were not stunted at an earlier survey round but were stunted at a later survey round (stunting is defined as $\mathrm{HAZ}<-2 \cdot 0)$.

tIncidence of recovery is the proportion of children who were stunted at an earlier survey round but were not stunted at a later survey round.

anthropometric procedures and rigorously trained field workers, and provided four diverse country contexts with which to study child growth patterns. However, several limitations of the data merit discussion. The Young Lives study began collecting data when the children were 6-17.9 months old, so length at birth is not consistently available. Round 1 data were collected during an age period in which growth faltering occurs in many LMIC settings $^{(1)}$, and indeed our data show this age-related decrease in length-for-age. We addressed this challenge by internally adjusting our data to age 12 months. Length was not measured at age 2 years, the age at which HAZ generally reaches its nadir ${ }^{(1)}$. However, data from the INCAP (Institute of Nutrition of Central America and Panama) nutrition supplementation study showed that HAZ at ages 6, 12 and 18 months are strongly correlated with HAZ at age 24 months $(r=0.74,0.83$ and 0.91 , respectively; all $P<0 \cdot 001$ ), suggesting that HAZ between the ages of 6 and 18 months can serve as a reasonable proxy for HAZ at age 24 months ${ }^{(24)}$. Additionally, having only three length/height measurements (at ages 1, 5 and 8 years) limits our ability to characterize post-infancy child growth patterns.

In the present analysis, the calculation of $Z$-scores used growth standards from two distinct populations. The child growth standards used to calculate $Z$-scores for the Young Lives cohorts at 1 year of age come from the longitudinal WHO Multicentre Growth Study, a population of exclusively or predominantly breast-fed children. The data for these growth standards end at 5 years of age, so the WHO developed reference charts for children older than 5 years based on cross-sectional data from the 1977 US National
Center for Health Statistics study of child growth, where feeding type was not controlled ${ }^{(22)}$. We used these WHO reference charts for older children in the calculation of $Z$-scores at 5 and 8 years of age. This can limit the comparability of the $Z$-scores at the three time points and suggests that the data should be interpreted carefully.

The results of the current analysis are based on data from four diverse country contexts, and we aimed to present and interpret country-specific findings while also discussing growth patterns that were common across the sites. We did not, however, attempt to explain sources of variation across sites in the magnitude of growth failure and the incidence of stunting and recovery from stunting, as such an analysis would require far more sites than the four in Young Lives and the models would quickly become saturated.

The present analysis has several strengths. When compared with other longitudinal studies that have collected child growth data, such as those participating in the COHORTS (Consortium of Health-Orientated Research in Transitioning Societies) collaboration ${ }^{(25)}$, the Young Lives study provides unique data with which to characterize child growth patterns. The Young Lives study provides more recent data on children born at about the same time that the Millennium Development Goals were established. The data were collected longitudinally within four diverse, population-based cohorts using a study-wide standardization and training process. With its emphasis on LMIC, the Young Lives study is well positioned to document the incidence and timing of stunting and recovery among post-infancy children in countries characterized by poor childhood nutrition and growth, the focus of the Millennium Development Goals. 
Our data demonstrate that while child growth trajectories throughout the pre-school and early school-age years are predicted in part by size at age 1 year, there is significant variation in growth after 1 year of age. This includes catchup growth in some children and faltering in others. These results suggest that while prevention of early-life stunting must continue to be a top priority, programme planners and implementers should consider identifying and targeting for further nutritional interventions children who nevertheless become stunted during infancy, as well as children at risk for later growth faltering. An important area for future research is identifying the factors that contribute to these later variations in growth.

\section{Acknowledgements}

Sources of funding: This study is based on research funded by the Bill \& Melinda Gates Foundation (Global Health Grant OPP1032713), the Eunice Shriver Kennedy National Institute of Child Health and Development (Grant R01 HD070993) and Grand Challenges Canada (Grant 0072-03 to the Grantee, The Trustees of the University of Pennsylvania). The data used in this study come from Young Lives, a 15-year, ongoing cohort study that investigates the changing nature of childhood poverty in Ethiopia, India (Andhra Pradesh), Peru and Vietnam (www.younglives.org.uk). Young Lives is corefunded by UK aid from the Department for International Development (DFID) and co-funded from 2010 to 2014 by the Netherlands Ministry of Foreign Affairs. The findings and conclusions contained herein are those of the authors and do not necessarily reflect positions or policies of the Bill \& Melinda Gates Foundation, the Eunice Shriver Kennedy National Institute of Child Health and Development, Grand Challenges Canada, Young Lives, the DFID or other funders. The funders had no role in the design, analysis or writing of this article. Conflicts of interest: The authors declare that they have no conflicts of interest. Ethics: Ethical approval was not required. Authors' contributions: M.E.P. was involved in the design of the Young Lives study as well as study implementation in Peru; E.A.L. and A.D.S. oversaw the initial design of the analysis, wrote the paper and had primary responsibility for final content; E.A.L. analysed the data. All authors interpreted the data, helped prepare the manuscript and (except for P.E., who passed away during the preparation of the manuscript) approved the final version.

\section{References}

1. Victora C, deOnis M, Hallal P et al. (2010) Worldwide timing of growth faltering: revisiting implications for interventions. Pediatrics 125, e473-e480.

2. Ashworth A (1986) Catch-up growth in children. Nutr Rev 44, 157-163.
3. Checkley W, Epstein L, Gilman R et al. (2003) Effects of acute diarrhea on linear growth in Peruvian children. Am J Epidemiol 157, 166-175.

4. deOnis M (2003) Commentary: Socioeconomic inequalities and child growth. Int J Epidemiol 32, 503-505.

5. Martorell R, Khan L \& Schroeder D (1994) Reversibility of stunting: epidemiologic findings from children in developing countries. Eur J Clin Nutr 48, Suppl. 1, S45-S47.

6. Norgan N (2000) Long-term physiological and economic consequences of growth retardation in children and adolescents. Proc Nutr Soc 59, 245-256.

7. Shah S, Selwyn B, Luby S et al. (2003) Prevalence and correlates of stunting among children in rural Pakistan. Pediatr Int 45, 49-53.

8. Walker S, Grantham-McGregor S, Himes J et al. (1996) Early childhood supplementation does not benefit the long-term growth of stunted children in Jamaica. J Nutr 126, 3017-3024.

9. Johnson D (2002) Adoption and the effect on children's development. Early Hum Dev 68, 39-54.

10. Nelson C, Zeanah C \& Fox N (2007) The effects of early deprivation on brain-behavioral development: The Bucharest Early Intervention Project. In Adolescent Psychopathology and the Developing Brain: Integrating Brain and Prevention Science, pp. 197-215 [D Romer and E Walker, editors]. New York: Oxford University Press.

11. Johnson D \& Gunnar M (2012) Growth failure in institutionalized children. In Children Without Permanent Parents: Research, Practice, and Policy. Monographs of the Society for Research in Child Development no. 301, 76(4), pp. 92-126 [RB McCall, MH Van Ijzendoorn, F Juffer et al., editors]. Boston, MA: Wiley-Blackwell.

12. Zeanah C, Gunnar M, McCall R et al. (2012) Sensitive periods. In Children Without Permanent Parents: Research, Practice, and Policy. Monographs of the Society for Research in Child Development no. 301, 76(4), pp. 147-162 [RB McCall, MH Van Ijzendoorn, F Juffer et al., editors]. Boston, MA: Wiley-Blackwell.

13. Crookston B, Penny M, Alder S et al. (2010) Children who recover from early stunting and children who are not stunted demonstrate similar levels of cognition. J Nutr 140, 1996-2001.

14. Morgane PJ, Austin-LaFrance R, Bronzino J et al. (1993) Prenatal malnutrition and development of the brain. Neurosci Biobehav Rev 17, 91-128.

15. Strauss RS \& Dietz WH (1998) Growth and development of term children born with low birth weight: effects of genetic and environmental factors. J Pediatr 11, 67-72.

16. Pollitt E, Gorman KS, Engle PL et al. (1993) Early supplementary feeding and cognition: effects over two decades. Monogr Soc Res Child Dev 58, 1-99.

17. Cheung Y \& Ashorn P (2010) Continuation of linear growth failure and its association with cognitive ability are not dependent on initial length-for-age: a longitudinal study from 6 months to 11 years of age. Acta Paediatr 99, 1719-1723.

18. Adair LS (1999) Filipino children exhibit catch-up growth from age 2 to 12 years. J Nutr 129, 1140-1148.

19. Barnett I, Ariana P, Petrou S et al. (2013) Cohort profile: the Young Lives study. Int J Epidemiol 42, 701-708.

20. World Health Organization (2008) Child Growth Standards. Training Course on Child Growth Assessment. Module B: Measuring a Child's Growth. http://www.who.int/childgrowth/training/en/ (accessed October 2012).

21. WHO Multicentre Growth Reference Study Group (2006) WHO Child Growth Standards based on length/height, weight and age. Acta Paediatr Suppl 450, 76-85.

22. deOnis M, Onyango A, Borghi E et al. (2007) Development of a WHO growth reference for school-aged children and adolescents. Bull World Health Organ 85, 660. 
23. World Health Organization, WHO Multicentre Growth Reference Study Group (2006) WHO Child Growth Standards: Length/Height-for-Age, Weight-for-Age, Weightfor-Length, Weight-for-Height and Body Mass Index-forAge: Methods and Development. Geneva: WHO; available at http://www.who.int/childgrowth/standards/en/
24. Stein AD, Melgar P, Hoddinott J et al. (2008) Cohort profile: the Institute of Nutrition of Central America and Panama (INCAP) Nutrition Trial Cohort Study. Int J Epidemiol 37, 716-720.

25. Richter LM, Victora CG, Hallal PC et al. (2012) Cohort profile: the Consortium of Health-Orientated Research in Transitioning Societies. Int J Epidemiol 41, 621-626. 